\title{
WIND TUNNEL TESTING OF A HIGH AUTHORITY AIRSPEED INSENSITIVE ROTOR BLADE FLAP
}

\author{
Joseph W Clement* and Diann Brei ${ }^{\dagger}$ \\ The University of Michigan \\ Ann Arbor, Michigan 48109-2125 \\ Ron Barrett ${ }^{\ddagger}$ \\ Auburn University \\ Aubum University, AL 36849-5338
}

\begin{abstract}
A viable active rotor blade flap system for vibration control needs to address the actuator authority, the sensitivity of flap pitch deflections to changes in angle of attack, aerodynamic moments generated by flap deflections themselves and inertial moments due to blade plunge motions. This paper presents the experimental wind tunnel results of a new active rotor blade flap system that has the potential to overcome these problems. This active rotor blade flap system is insensitive to airspeed, angle of attack changes and plunge motions because of a novel high authority actuation system, C-blocks, and the utilization of a mass and aerodynamically balanced flap. C-block actuators are curved piezoelectric benders which can provide over twice the force of comparable straight benders without requiring the use of external leveraging systems necessary with piezoelectric stacks. The initial wind tunnel results proved that the use of C-block actuators and a mass and aerodynamically balanced flap can generate flap deflections in excess of $17^{\circ}$ peak-topeak that are independent of airspeed. Additionally, it was proven that the C-block driven flap is capable of creating pitch changes of the entire rotor blade section demonstrating potential for full flight control.
\end{abstract}

\section{Introduction}

Because of the large vibrations present in modern rotorcraft, researchers have actively investigated the use of piezoelectric actuators to control the vibrations using

${ }^{*}$ Graduate Student, Department of Mechanical

Engineering and Applied Mechanics

${ }^{\dagger}$ Assistant Professor, Department of Mechanical

Engineering and Applied Mechanics

${ }^{\ddagger}$ Associate Professor, Department of Aerospace Engineering

Copyright $@ 1999$ The American Institute of Aeronautics and Astronautics Inc. All rights reserved.
Higher Harmonic Control (HHC) and Individual Blade Control (IBC). Piezoelectric actuation has been used instead of conventional methods, such as hydraulics and electric motors, because of the weight and power savings along with the increased bandwidth. Standard piezoelectric stack ${ }^{1,2}$ and bimorph $h^{3,4}$ actuation schemes have been studied along with tapered bimorphs ${ }^{5,6}$ and hybrid systems incorporating both piezoelectrics and hydraulics ${ }^{7,8,9}$. These studies have shown great promise in the control of rotor blade vibrations.

Unfortunately, most of the current active flap systems that incorporate piezoelectric actuators have flap deflections that are coupled to changes in angle of attack. Because of this, the performance of current active flap systems is significantly degraded in the turbulent and gusting airflow of the helicopter's flight domain. As the rotor sweeps the azimuth, the angle of attack of the individual blade section changes. The induced aerodynamic hinge moment experienced by current active flap systems can reduce the flap deflection below the $10^{\circ}$ peak-to-peak at $\mathrm{N} / \mathrm{rev}$ which are necessary to generate the required net change in lift for vibration control. There are two main reasons for the loss in flap deflection with changes in angle of attack and increasing airspeed. The first is due to the limited actuator authority and the second is due to the flap design.

There are a number of different piezoelectric actuation schemes which are employed in active rotor blade flaps. One of the original schemes incorporated straight bimorphs which can generate large deflections but have low force ${ }^{10}$. For example, straight bimorphs that give free deflections of approximately $100 \mu \mathrm{m}$ can only produce blocking forces on the order of $4 \mathrm{~N}^{11}$. Recently, researchers have overcome this by tapering the bender by adjusting the thickness of the substrate or utilizing more piezoelectric layers of varying length 
which can increase the output work of the straight bender ${ }^{5,6}$. However, the deflection, which is transverse to its length, is sometimes a problem for active rotor blade flap systems due to interference between the bender and the surface of the rotor blade. Stacks, on the other hand, easily create the necessary force. However, external leveraging systems are often required to achieve large deflections and these systems can rob the actuator of as much as $80 \%$ of its energy density $^{12}$. Thus, many of the current piezoelectric actuation schemes can not overcome the aerodynamic hinge moments generated as the flap is deflected.

In addition, increasing the actuator authority alonc does not completely overcome the airspeed and angle of attack sensitivity problem because it does not decouple the flap deflection from either airspeed or angle of attack. Most of the current active flap systems use conventional flaps with hinges near the leading edge. These flaps experience large adverse aerodynamic hinge moments as the flap is deflected. As airspeed is increased, the aerodynamic hinge moment increases and consequently flap deflection is significantly degraded. Similarly, with a leading edge hinge, the adverse pitching moments on the flap increase with angle of attack changes and drive the flap into the wind.

To overcome the problem of low flap deflections that are sensitive to increasing airspeed and angle of attack changes, a balanced active flap design was created that incorporates a novel high authority actuation scheme, C-blocks. This paper presents the active rotor blade flap system design along with experimental characterization of the actuation system. Also presented are the wind tunnel experiments conducted to explore the potential of this new system to generate high flap deflections that are independent of airspeed.

\section{Active Rotor Blade Flap System Design}

The active rotor blade flap system utilized in this research was designed from both actuation and aerodynamic standpoints simultaneously. Large llap deflections were achieved by designing a flap which minimizes the control loads required by the actuator, and tailoring the actuator performance to the requirements of active vibration control. To reduce the sensitivity of flap deflection to airspeed, a mass and aerodynamically balanced flap was employed. This was accomplished by co-locating the center of gravity, center of pressure and flap hinge axis. The balancing has several major benefits over a conventional, nonbalanced flap. First, the mass balancing increases the frequency response by reducing the inertial load of the flap. Second, the mass balancing helps to decouple the flap deflection from blade plunge motions aiding in the resistance of the flap system to control surface lock. Third, the aerodynamic balancing nearly eliminates any moment generated by aerodynamic loads on the flap, resulting with flap deflections that are insensitive to changes in attached airflow over the blade. As a result, a mass and aerodynamically balanced flap allows for large deflections that are independent of airspeed.

Even with the added benefits of a balanced flap, a high authority actuation system is still necessary. Thus an actuation system incorporating C-block actuators was designed. The C-block is an internally leveraged piezoelectric bender much like the more common straight bender with the exception that it is curved (Figure1). A unimorph design was chosen for this research because it can be pre-compressed to eliminate any tensile loading in the piezoceramic material. The C-block is poled radially resulting in a circumferential strain upon the application of an electric lield. Individual C-blocks can be combined end to end to create serial actuators. The actuation system chosen consists of two serial C-block actuators aligned in the

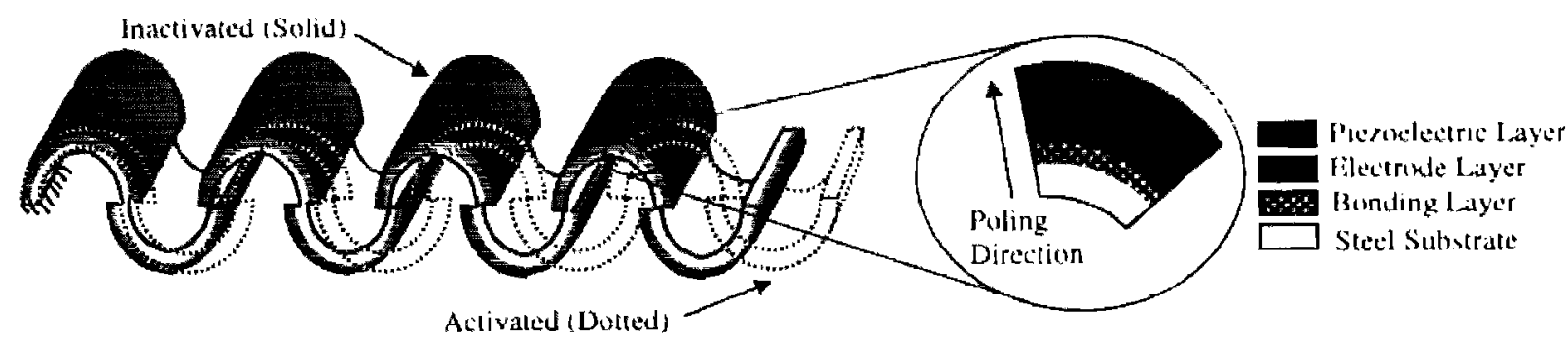

Figure 1: C-block Actuator Design and Operation The individual C-block is a semicircular piczoclectric unimorph bender. Individual C-blocks can be combined in sertes to increase the dellection periormance without incurring a Inss in force. The $C$. block generates approximately 2.67 times the force and 0.4115 simes the deflection of an equivalent straight hender. 


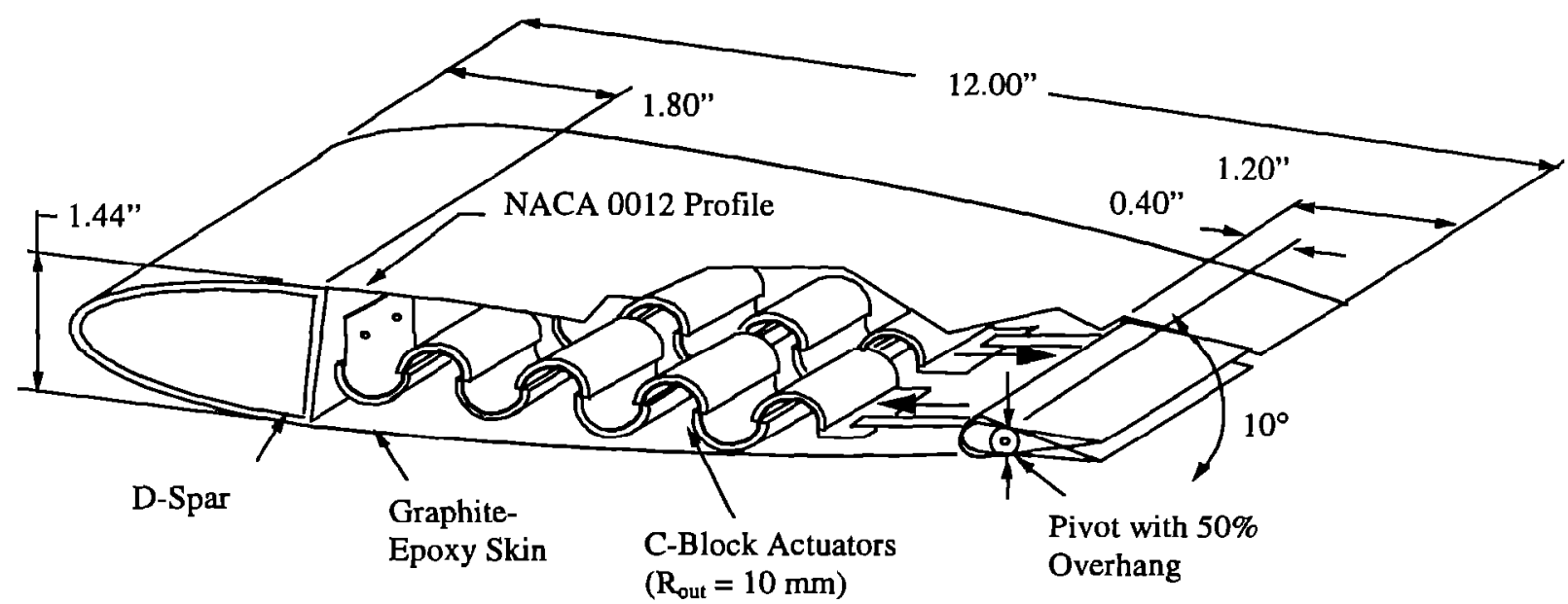

Figure 2: Active Rotor Blade System Design The wind tunnel test specimen consisted of a NACA 0012 airfoil with a 10\% chord flap. The hinge axis of the flap is aligned with the center of gravity and center of pressure to reduce the inertial load and decouple the flap deflection from airspeed. The actuators are excited out of phase to drive the mass and aerodynamically balanced $10 \%$ chord flap.

span-wise direction of the rotor blade section. The actuators are excited out of phase to operate in a pullpull mode to create the flap deflections (Figure 2).

The net deflection of the serial C-block actuator acts along the actuator's length, eliminating the possibility of reduced deflection due to interference with the skin of the helicopter blade which can occur with straight benders. The unique curved shape of the C-block generates approximately 2.67 times the force, and 0.405 times the deflection of a comparable straight bender, resulting in an $8 \%$ increase in work output ${ }^{13}$. Additionally, the curved shape allows individual Cblocks to be linked together in series, linearly increasing the actuator's deflection without affecting it's blocking force ${ }^{14}$. This allows the performance of a C-block actuator to be tailored directly to the application without resorting to an external leveraging system. This aids in efficient energy transfer since it has been shown that external leveraging system can result in 65 to $80 \%$ losses in energy density ${ }^{12}$.

\section{Implementation of the Wind Tunnel Test Article}

The balanced flap and novel C-block actuation system designs were fabricated, characterized, and then integrated together to complete the active flap system.

\section{Rotor Blade Section and Active Flap}

For the rotor blade flap system, a 12 inch chord NACA 0012 rotor blade section with a $10 \%$ chord flap was used for the Wind Tunnel Test Specimen. The blade section and flap were constructed in three primary phases. First, male mandrels were fabricated from high temperature polyester casting resin and held to $0.1 \%$ dimensional tolerances. Second, Thornel ${ }^{\mathrm{TM}}$ graphiteepoxy cloth was laid up on the mandrels and cured under pressure. Lastly, the composite skins were removed and assembled (Figure 3$)^{15}$. Leading edge counter balances were added to the rotor blade section after the C-block actuator were integrated to position the center of gravity of the entire system over the quarter-chord. The fully symmetrical NACA 0012 airfoil has an aerodynamic center located on the quarter-chord as all full symmetrical airfoils do for attached subsonic flow, thereby aerodynamically balancing attached flow aerodynamic moments about the quarter-chord.

\section{C-block Actuation System}

By concurrently designing the actuator and rotor blade, it was determined that an actuation system capable of a free deflection of $110 \mu \mathrm{m}$ and a blocking

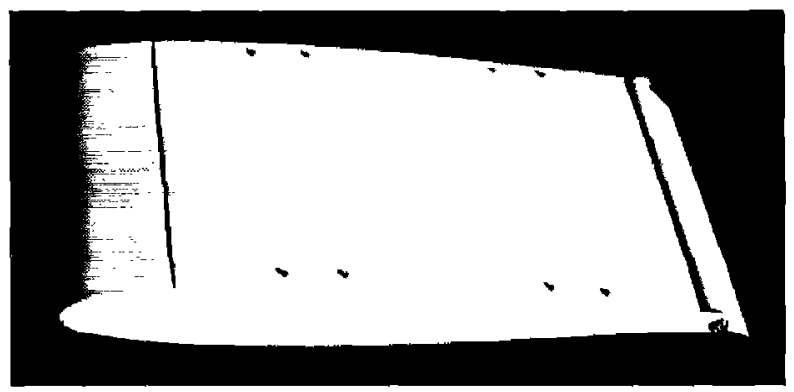

Figure 3: Assembled Rotor Blade Section The rotor blade section and flap were fabricated of Thomel ${ }^{\mathrm{TM}}$ P-75 graphiteepoxy cloth. All components were held to $0.1 \%$ dimensional tolerances. 


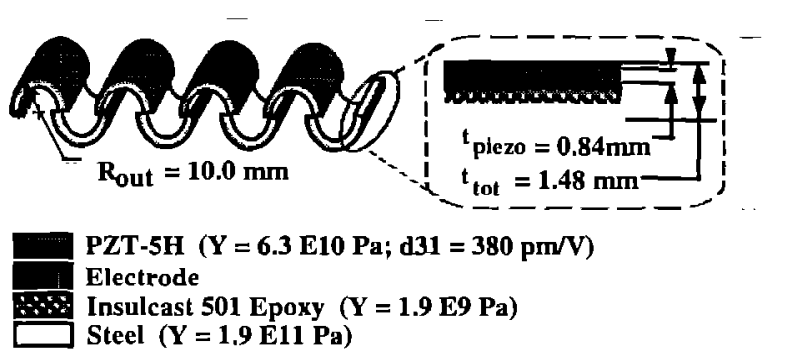

a) C-block Actuator Configuration

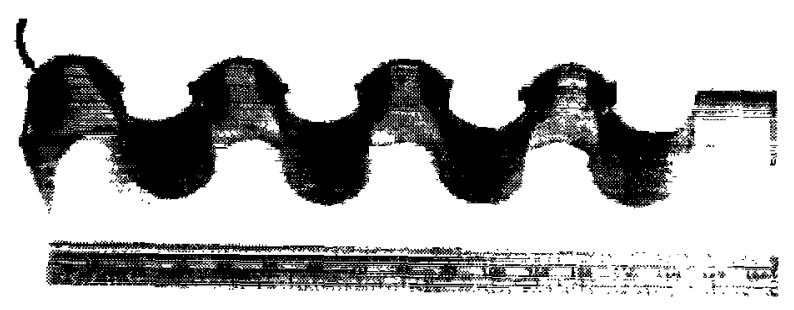

\section{b) C-block Actuator Photo}

Figure 4: C-block Wind Tunnel Actuator Prototype The two PZT-5H C-block actuators used for the wind tunnel testing were each comprised of eight C-blocks, each of $10 \mathrm{~mm}$ outside diameter bonded to a stainless steel substrate.

force of approximately $10 \mathrm{~N}$ would be sufficient to generate the initial goal of $10^{\circ}$ peak-to-peak of flap deflection. The performance tailorability of the Cblock architecture resulted in many options to meet these design requirements. A conservative actuation system was chosen which consisted of two actuators each comprised of eight C-blocks in series. Each acluator was constructed of eight PZT-5H half circles of $10 \mathrm{~mm}$ diameter bonded to a single stainless steel substrate formed into a corrugated shape (Figures 4$)^{15}$. The actuators were designed to meet the design requirements of $10^{\circ}$ peak-to-peak of flap deflection while operating at approximately $50 \%$ of the manufacturer's maximum recommended electric field.

Prior to integration with the rotor blade section, the performance of each C-block actuator was characterized. This allowed for the determination of the deflection lost as a result of the integration of the actuators and the blade section. Two types of tests were performed. First, the quasi-static performance of each actuator was examined to determine the output of the actuators in the absence of dynamic amplification. Second, the dynamic frequency response of the actuators was examined to verify the location of the natural frequencies and the bandwidth of the actuators.

Quasi-static excitation of each actuator at $150 \mathrm{~V}$ ( $44 \%$ of maximum recommended voltage) resulted with

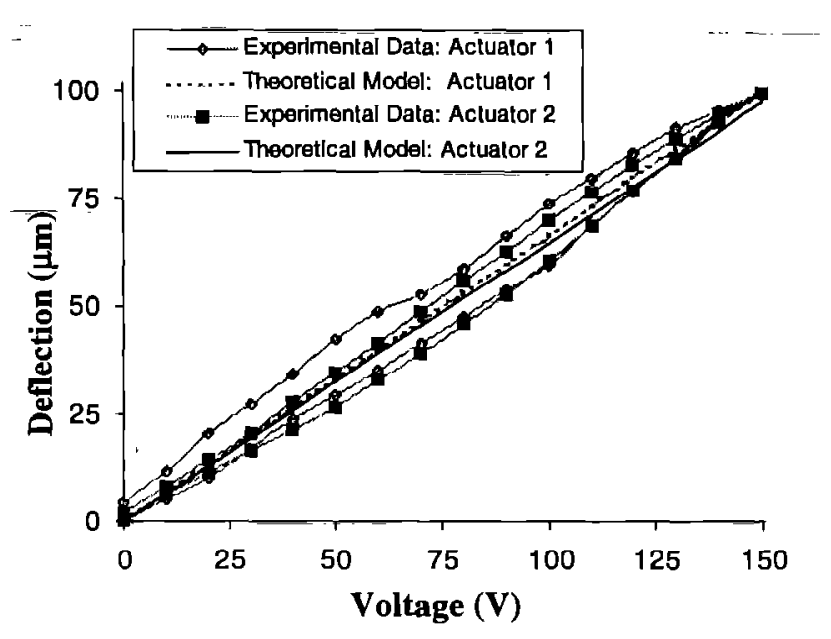

Figure 5: C-block Actuator Deflection-Voltage Response The deflection of both actuators 1 and 2 as a function of voltage. A maximum deflection of approximately $100 \mu \mathrm{m}$ was obtained for each actuator at $150 \mathrm{~V}$ (45\% of the maximum rated voltage).

a free deflection of approximately $100 \mu \mathrm{m}$ and a corresponding blocking force of approximately $10 \mathrm{~N}$ (Figures 5,6). The analytical model predicted the response of the actuators with an average error of $5 \%$. The actuators were tested dynamically over a $5000 \mathrm{~Hz}$ frequency range to insure that the actuators could provide vibration control at frequencies according to at

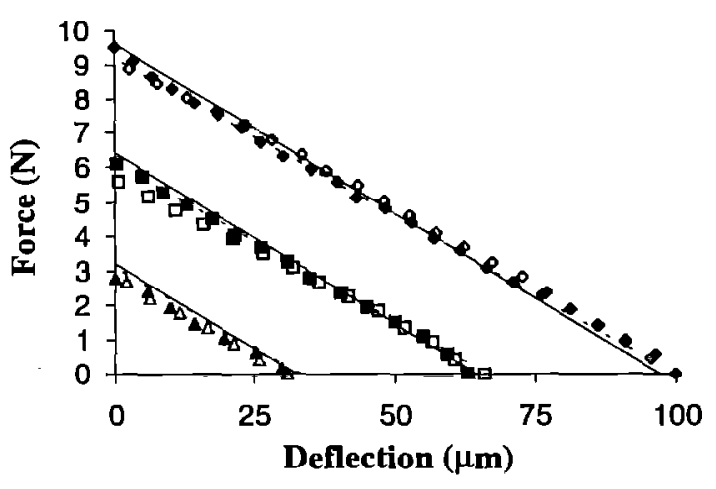

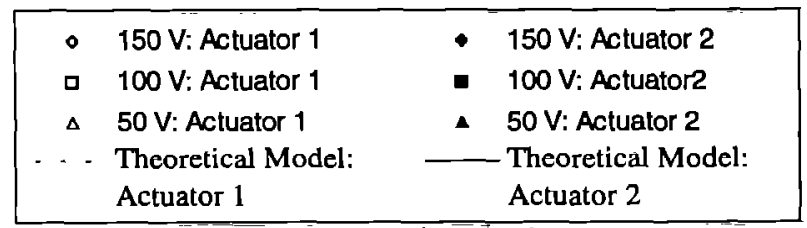

Figure 6: C-block Actuator Force-Deflection Response The force and deflection output of actuators 1 and 2 in response to input voltages of 50,100 , and $150 \mathrm{~V}$. A blocking force of approximately $9.8 \mathrm{~N}$ was obtained for each actuator at $150 \mathrm{~V}$ ( $45 \%$ of the maximum rated voltage). 
least $4 / \mathrm{rev}(28 \mathrm{~Hz})$. The first and second natural frequencies were observed at approximately $16 \mathrm{~Hz}$ and $250 \mathrm{~Hz}$ respectively (Figure 7).

These bench-top tests demonstrated that the Cblock actuators could provide the necessary deflection of $110 \mu \mathrm{m}$ to generate the desired $10^{\circ}$ peak-to-peak of flap deflection with a bandwidth of at least $28 \mathrm{~Hz}$ at $50 \%$ of the maximum recommended voltage. If the voltages are increased to the maximum rated value of $340 \mathrm{~V}(-10.2 \mathrm{~V} / \mathrm{mil})$, the actuators are expected to deflect $225 \mu \mathrm{m}$. This would result in a flap deflection of $20^{\circ}$ peak-to-peak if no losses were incurred in the integration of the flap to the actuators. The $28 \mathrm{~Hz}$ bandwidth is achieved upon integration because the natural frequencies increase upon application of the pre-load applied to the actuators when bolted in the flap system. Additionally, the modal amplitude of the first natural frequency decreases because the boundary conditions are altered from the near cantilevered state during the bench-top testing of the individual actuators, to the near pinned end conditions of the actuators when connected to the flap spindle and main spar.

\section{System Integration}

Integration of the actuators and the blade section was critical since any unnecessary weight or friction can significantly reduce the bandwidth and the magnitude of flap deflections. Therefore a concerted effort was made to minimize the inertial and frictional loading on the actuators resulting in the following integration scheme (Figure 8). Light weight, carbon fiber crossbars were epoxied to the end of each actuator to provide an anchoring point for the Kevlar cords used to transfer the actuator deflection to the flap. Two
Kevlar cords were attached to the lower crossbar, fed through a slot in the hollow trailing edge flap, wrapped 1.5 times around the flap spindle, and attached to the upper crossbar with two turnbuckles. The actuators were slid onto cap screws mounted on the rotor blade section's main spar and lock nuts were used to apply the pre-load and hold the actuators in place. The turnbuckles were used to fine-tune the individual tension on each actuator during final assembly. The actuators were electrically isolated from the rotor blade section and wired out of phase to drive the trailing edge flap.

The large shear and tensile strength of the Kevlar allowed for the application of a much greater pre-load on the actuators as compared to other attachment methods tested such as brass shim stock or steel music wire. As the pre-load is increased, the piezoceramic is placed further into compression, where the ceramic is very strong. Therefore, through the use of the Kevlar cords, the risk of damaging the ceramic due to any tensile loading is greatly diminished. The increased pre-load also raises the natural frequencies of the system resulting in a much greater bandwidth. Lastly, the Kevlar cords, consisting of many fine individual threads, exhibit excellent fatigue failure properties, which other attachment methods, such as brass shim stock and steel music wire did not possess.

\section{Wind Tunnel Experimental Studies}

Following integration of the active flap system, a series of wind tunnel tests were conducted to verify that the active flap system is capable of large flap deflections independent of airspeed and that these flap deflections can induce pitch changes in the entire rotor

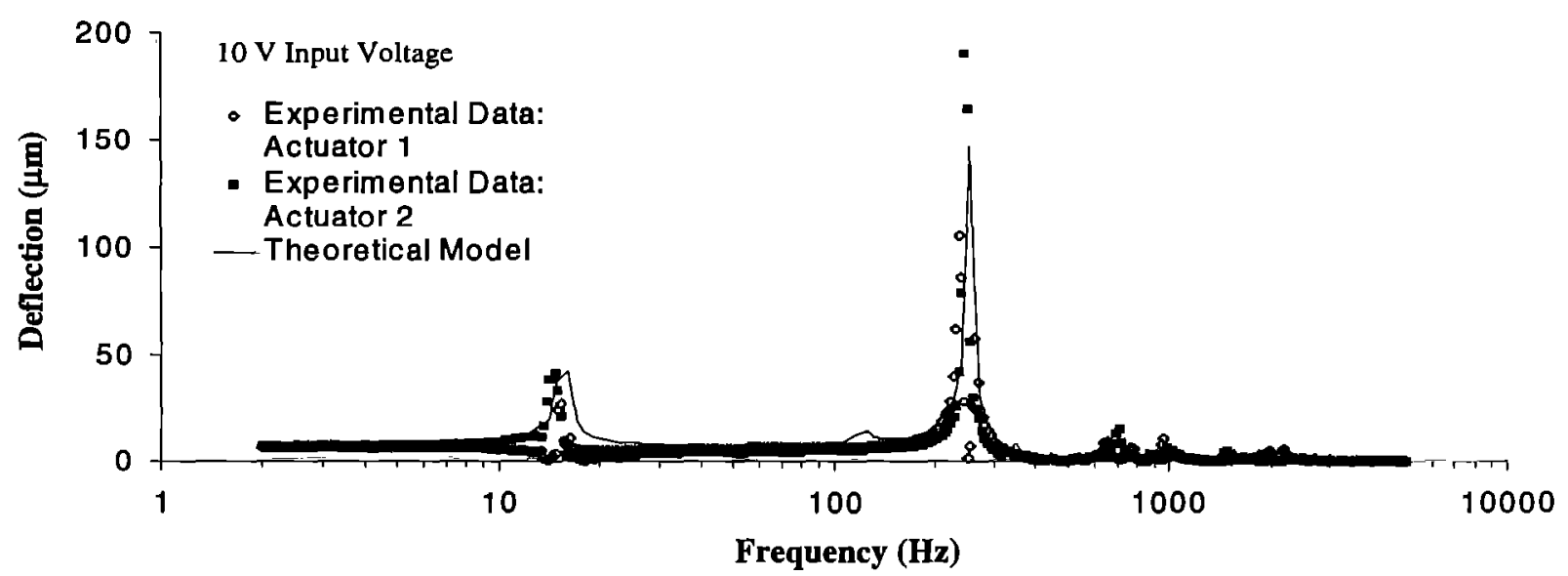

Figure 7: C-block Actuator Dynamic Response The deflection of actuators 1 and 2 in response to a sinusoidal $10 \mathrm{~V}$ input signal applied swept from 1 to $5000 \mathrm{~Hz}$. The first and second natural frequencies were located at $16 \mathrm{~Hz}$ and $250 \mathrm{~Hz}$ respectively for both actuators. 


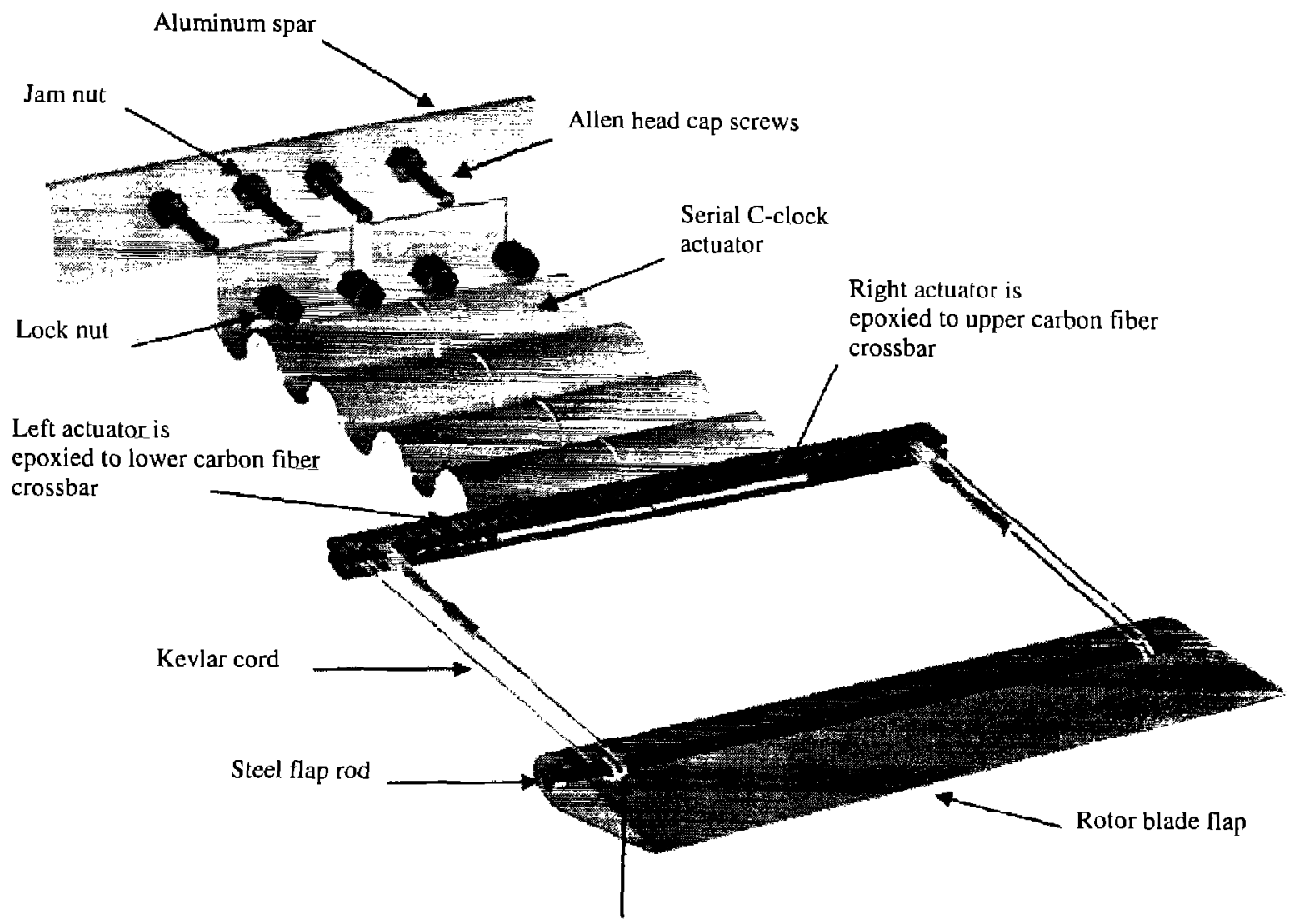

Kevlar cord wraps around flap rod

Figure 8: Integration Scheme for the Active Rotor Blade Flap System The C-blocks designed for the active rotor blade flap consisted of two side-by-side serial actuators connected to the flap spar by a Kevlar cord. The actuators are mounted to the main spar on allen head cap screws. The position of the mounting lock nuts adjusts the pre-load on the actuators to insure only compressive loads are experienced by the piezoceramic.

blade section. The tests were conducted in the three foot by four foot subsonic wind tunnel at Auburn University at airspeeds of 0,50 , and $100 \mathrm{ft} / \mathrm{s}$. A sinusoidal input signal was supplied by a Tektronix CFG280 signal generator and amplified by an ACX 1224/5 amplifier (Figure 9). The 12" chord, 6" span, NACA 0012 blade section with $10 \%$ chord flap was mounted between a pair of 30" square splitter plates (Figure 10). The right splitter plate was made from 0.080" thick aluminum and housed a precision bearing at the location corresponding the blades sections quarter chord. The left splitter plate was made of Plexiglas so that the pitch rotations could be observed. A circumferential slot was cut out of both splitter plates to allow clearance for the extension of the flap spindle beyond the span of the blade section. The blade section was mounted at the quarter-chord on the bearings located on the splitter plates. The blade section was mass and aerodynamically balanced to counter any adverse pitching moments. Electrical leads entered the blade section through a small hole located just in front of the quarter-chord. The adverse pitching moments generated by the presence of the electrical leads were measured to be less than 0.01 in-oz, which was essentially negligible. Flap deflections were obtained by reflecting a laser, mounted beneath the wind tunnel, off a small mirror positioned on the flap spindle outside of the splitter plates. The reflected beam was directed onto a calibrated scale mounted inside the wind tunnel. A second calibrated scale was located on the splitter plates, along the circumferential slot, to measure the changes in the blade pitch.

To evaluate the potential of the system for both vibration control and main rotor control, the system was tested with two types of tests. First the quasi-static and dynamic performance of the flap were examined with the blade section fixed. Second, the blade section was allowed to freely rotate about the quarter-chord in response to flap deflections. 


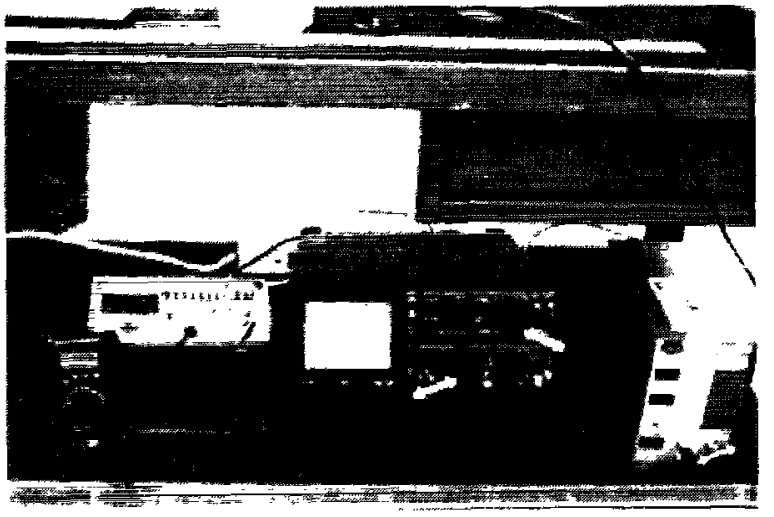

Figure 9: Wind Tunnel Test Equipment Input signals were supplied by a Tektronix CFG280 signal generator and amplified with an ACX 1224/5 amplifier.

\section{Flap Deflection Experiments}

The first series of tests were conducted with the blade section fixed at $0^{\circ}$ angle of attack. The quasistatic tests were performed to determine the true performance of the system in the absence of dynamic amplification and verify that the aerodynamic balancing of the flap produced deflections that were independent of airspeed. The dynamic tests were performed to determine the locations of the natural frequencies of the system and verify that the system was capable of achieving large deflections over a broad frequency range. The broad bandwidth and large deflections are necessary if the active flap is to operate in an IBC system. Since the system was not designed to operate

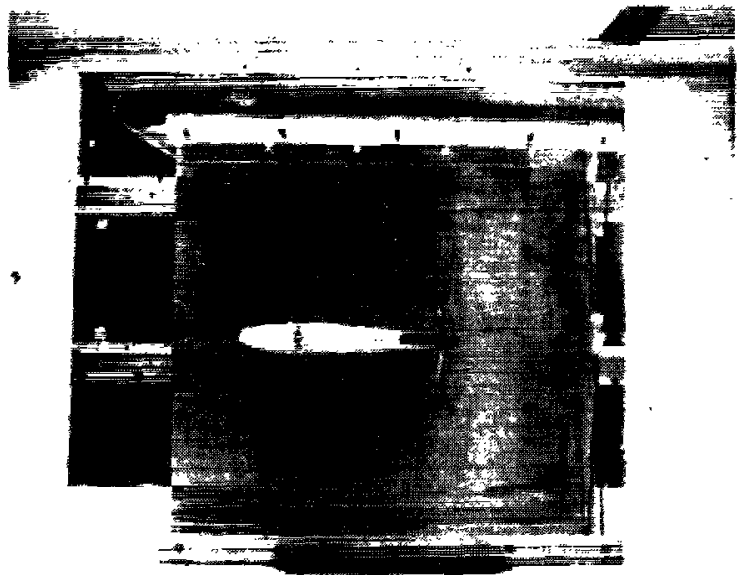

Figure 10: Wind Tunnel Test Rig Wind tunnel testing was conducted in the three foot by four foot subsonic wind tunnel at Auburn University. The 12" chord, 6" span, blade section were mounted between 30" splitter plates. The near plate was constructed of Plexiglas to allow for observation of the system. at resonance, the locations of the natural frequencies were critical.

\section{Quasi-static Fixed Blade Flap Tests}

To investigate the quasi-static performance of the flap system, a $1 \mathrm{~Hz}$ input signal was applied to the Cblock actuators. The signal was increased from $0 \mathrm{~V}$ to $190 \mathrm{~V}$ with airspeeds of 0,50 , and $100 \mathrm{ft} / \mathrm{s}$. The quasistatic tests demonstrated that the flap deflections in excess of $9^{\circ}$ peak-to-peak could be commanded at less than $60 \%$ of the rated voltage of the C-blocks (Figure 11). Testing at airspeeds from 0 to $100 \mathrm{ft} / \mathrm{s}$ demonstrated no degradation in flap deflection as a function of airspeed. As the tunnel speed was increased beyond $100 \mathrm{ft} / \mathrm{s}$, racking was observed in the test rig. Accordingly, $100 \mathrm{ft} / \mathrm{s}$ was set as the upper bound for these tests. If the voltage were increased to the maximum rated voltage of $340 \mathrm{~V}$, quasi-static flap deflections of approximately $16^{\circ}$ peak-to-peak are expected.

This series of quasi-static tests demonstrated that aerodynamically balanced flaps could easily be driven to appreciable deflections with no degradation due to airspeed. This is in strong contrast to conventional flaps, which show significant loss in deflection as airspeed is increased as a result of the adverse pitching moment created by aerodynamic loads. Unlike previous approaches to adaptive flaps, this system will maintain consistent levels of flap deflection independent of airspeed without requiring an oversized actuation system to overcome the large aerodynamic hinge moment inherent with conventional flaps.

\section{Dynamic Fixed Blade Flap Tests}

A second series of fixed blade tests were conducted to explore the dynamic performance of the flap system (Figure 12). The dynamic flap tests were performed at voltages of 75 and $190 \mathrm{~V}$ and swept from 0 to $120 \mathrm{~Hz}$. The $75 \mathrm{~V}$ test was used to obtain the frequency response of the flap through resonance without risk of damaging the system in these early tests. The second run was performed at $190 \mathrm{~V}$ to demonstrate that the flap could dynamically achieve large deflections independent of airspeed. The $190 \mathrm{~V}$ test run was conducted from 0 to $45 \mathrm{~Hz}$. Above $45 \mathrm{~Hz}$ the Kevlar cords began to slip on the flap spindle. This occurred because the cords were not glued to the spindle during these initial tests to allow for any adjustments that might be necessary. All tests were conducted at airspeeds of 0,50 , and $100 \mathrm{ft} / \mathrm{s}$.

Dynamic testing of the flap system demonstrated a small amplitude increase due to a first natural frequency 


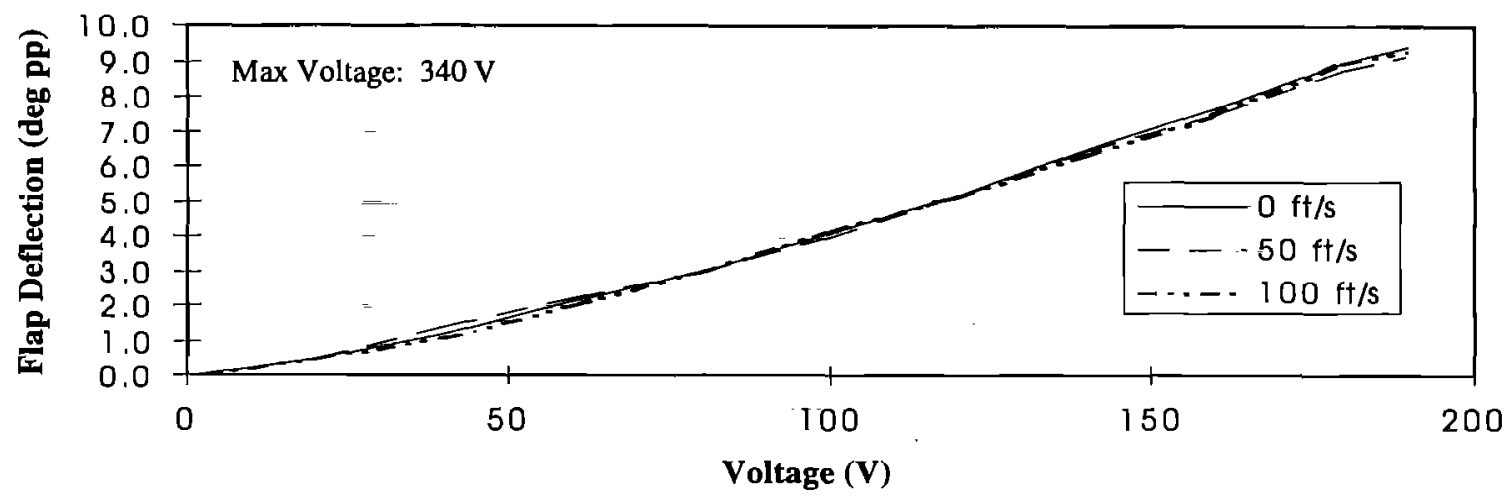

Figure 11: Quasi-static Wind Tunnel Flap Deflection Peak-to-peak flap deflection as a function of applied voltage applied at $1 \mathrm{~Hz}$. Tests were conducted at airspeeds of 0,50 , and $100 \mathrm{ft} / \mathrm{s}$ with the blade section fixed at $0^{\circ}$ pitch. Flap deflections in excess of $9^{\circ}$ peak-to-peak were obtained at $190 \mathrm{~V}, 60 \%$ of the maximum rated field, and showed no degradation with airspeed.

resonance near $25 \mathrm{~Hz}$ and a corner frequency was observed to be in excess of $100 \mathrm{~Hz}$. This first system mode represents only a small increase in flap deflection. The flap deflection increases smoothly between the first and mode and the more predominant second resonance frequency at approximately $60 \mathrm{~Hz}$. As a result, the bandwidth of the system is considered to be approximately $60 \mathrm{~Hz}$, because the very low amplitude first natural frequency will not provide significant difficulties for a control system. The airspeed had a negligible effect on the flap deflection away from resonance. Near resonance, the flap deflection was observed to experience a small reduction in deflection as airspeed was increased. This expected result is due to the increase in the aerodynamic damping associated with higher airspeeds. This degradation in flap deflection is unavoidable, but is minimal and only occurs near resonance. As the system is not intended to be operated at resonance, this degradation does not impose any limitations on the active flap system.

Dynamic testing at $190 \mathrm{~V}$ demonstrated that the aerodynamic balancing of the flap allowed for large dynamic flap deflections and a low sensitivity to airspeed, with flap deflections of $11.8^{\circ}$ peak-to-peak at $0 \mathrm{ft} / \mathrm{s}, 11.5^{\circ}$ peak-to-peak at $50 \mathrm{ft} / \mathrm{s}$, and $11.3^{\circ}$ peak-topeak at $100 \mathrm{ft} / \mathrm{s}$ at $28 \mathrm{~Hz}$. At the maximum frequency tested of $45 \mathrm{~Hz}$, flap deflections of approximately $17^{\circ}$ peak-to-peak were obtained. It is expected that if the voltage was increased to the maximum rated voltage of $340 \mathrm{~V}$, flap deflections nearing $20^{\circ}$ peak-to-peak at 28 $\mathrm{Hz}$, and $30^{\circ}$ peak-to-peak at $45 \mathrm{~Hz}$ could be achieved. The jagged response observed in the low voltage dynamic test near resonance is a result of vibrations of the test rig. This response is only observed when the system was mounted between the splitter plates. Previous testing on the bench-top, without the wind

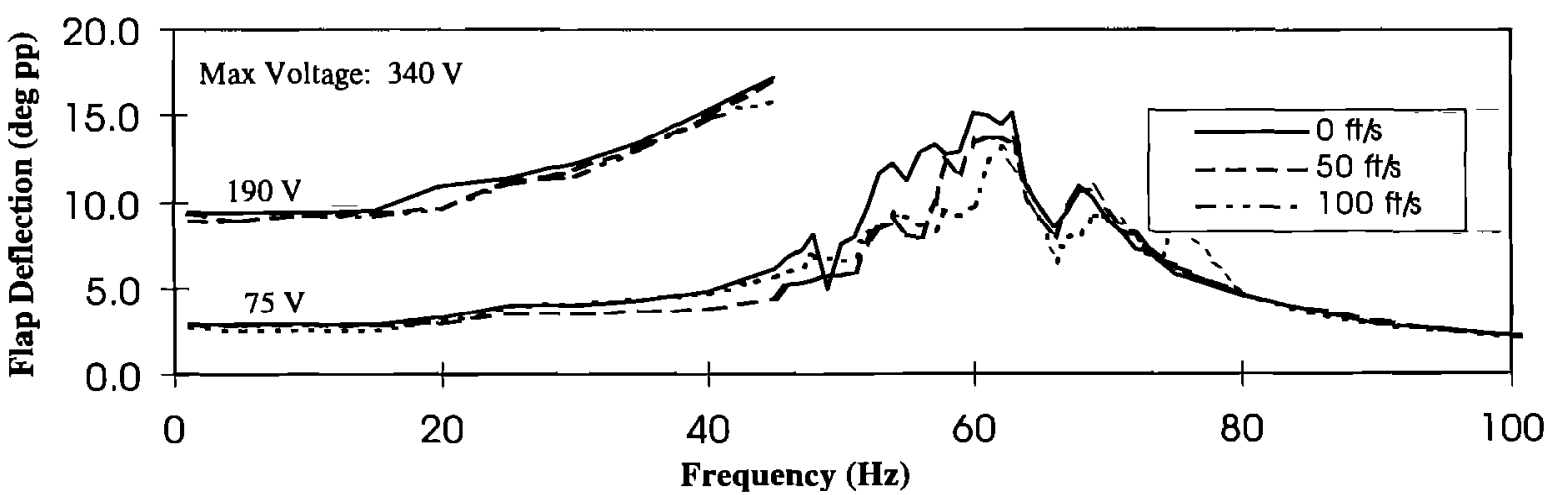

Figure 12: Dynamic Wind Tunnel Flap Response The dynamic response of the flap with the blade section fixed at $0^{\circ}$ pitch was examined over a $100 \mathrm{~Hz}$ frequency range. The first significant resonance peak was observed at $62 \mathrm{~Hz}$. Flap deflections at 28 $\mathrm{Hz}$ of approximately $11.8^{\circ} \mathrm{pp}$ at $0 \mathrm{ft} / \mathrm{s}, 11.5^{\circ} \mathrm{pp}$ at $50 \mathrm{ft} / \mathrm{s}$ and $11.3^{\circ} \mathrm{pp}$ at $100 \mathrm{ft} / \mathrm{s}$. At a frequency of $45 \mathrm{~Hz}$, flap deflections of approximately $17^{\circ}$ peak-to-peak were obtained. The jagged response near resonance is a result of vibrations in the test rig, and not the active flap system. 
tunnel splitter plates, demonstrated the smooth response characteristic of the active flap system ${ }^{15}$.

Dynamic testing proved that the aerodynamic and mass balancing of the flap, combined with the high authority C-block actuators results in large flap deflections that are insensitive to airspeed and angle of attack changes. As a result, the active flap system should not experience any performance degradation in response to the gust loads prevalent in helicopter flight. The flap could be commanded over a frequency range of nearly $60 \mathrm{~Hz}$, representing the potential to control many modes of vibration. The $60 \mathrm{~Hz}$ band width of the 12" chord test specimen corresponds to approximately $8.5 / \mathrm{rev}$, considering a $46 \%$ scale YUH-61 rotor system, or $8.8 / \mathrm{rev}$, considering a $92 \%$ scale OH-58 rotor system, or $9.8 / \mathrm{rev}$, considering a $178 \%$ scale Boeing $500 \mathrm{E}$ rotor blade. Thus the system has the potential of handling most HHC or IBC system commands, even for the five-bladed $500 \mathrm{E}$ rotor system.

\section{Blade Pitch Deflection Experiments}

Following the fixed blade testing, the blade section was unlocked and allowed to rotate freely about the quarter-chord. The blade section was mass and aerodynamically balanced about the quarter-chord so that only unsteady aerodynamic and inertial loads were present. Two series of tests were conducted to measure the blade pitch deflections in response to both static and dynamic flap deflections. These tests were performed to demonstrate the ability of the flap to induce a pitching moment on the entire blade section.

\section{Static Blade Pitch Tests}

The response of the blade section to near static $(\sim 0.1 \mathrm{~Hz})$ flap deflections was determined to isolate the performance of the system from any unsteady aerodynamic and inertial moments. The test was performed by applying a DC voltage to the C-block actuators and measuring the pitch of the blade section as a result of the flap's deflection for a tunnel speed of $50 \mathrm{ft} / \mathrm{s}$. The voltage was increased in $10 \mathrm{~V}$ increments from $20 \mathrm{~V}$ to $190 \mathrm{~V}$ and then to the amplifier's limit of approximately $194 \mathrm{~V}$. Testing at $50 \mathrm{ft} / \mathrm{s}$ demonstrated that the blade pitch deflection increased linearly with applied voltage once a voltage of $50 \mathrm{~V}$ was reached (Figure 13). The nonlinear response prior to $50 \mathrm{~V}$ is observed because the flap deflection is still within the boundary layer of the blade section for the low voltage. For an applied voltage of $194 \mathrm{~V}$, a maximum blade pitch deflection of $25^{\circ}$ peak-to-peak was obtained.

These static free blade tests demonstrate that at $60 \%$ of the rated voltage, blade pitch deflections of $25^{\circ}$ peak-to-peak can be obtained in response to near static flap deflections. Because most rotor blade systems operate with blade pitch deflections on this order, the C-block driven active flap system shows potential for full flight control as well as HHC and IBC.

\section{Dynamic Blade Pitch Tests}

The dynamic response of the blade section was obtained to determine to potential of the system for main collective control at airspeeds of 50 and $75 \mathrm{ft} / \mathrm{s}$ (Figure 14). The voltage was held constant at $194 \mathrm{~V}$ while the frequency was increased from $0.1 \mathrm{~Hz}$ to $5 \mathrm{~Hz}$. The testing showed the characteristic decay curve with a comer frequency of under $1 \mathrm{~Hz}$. Blade deflections of $25^{\circ}$ peak-to-peak were observed for both airspeeds of 50 and $75 \mathrm{ft} / \mathrm{s}$ for an excitation frequency of $0.1 \mathrm{~Hz}$. As the frequency was increased to $1 \mathrm{~Hz}$, approximate blade pitch deflections of $4^{\circ}$ peak-to-peak at $50 \mathrm{ft} / \mathrm{s}$, and $2^{\circ}$

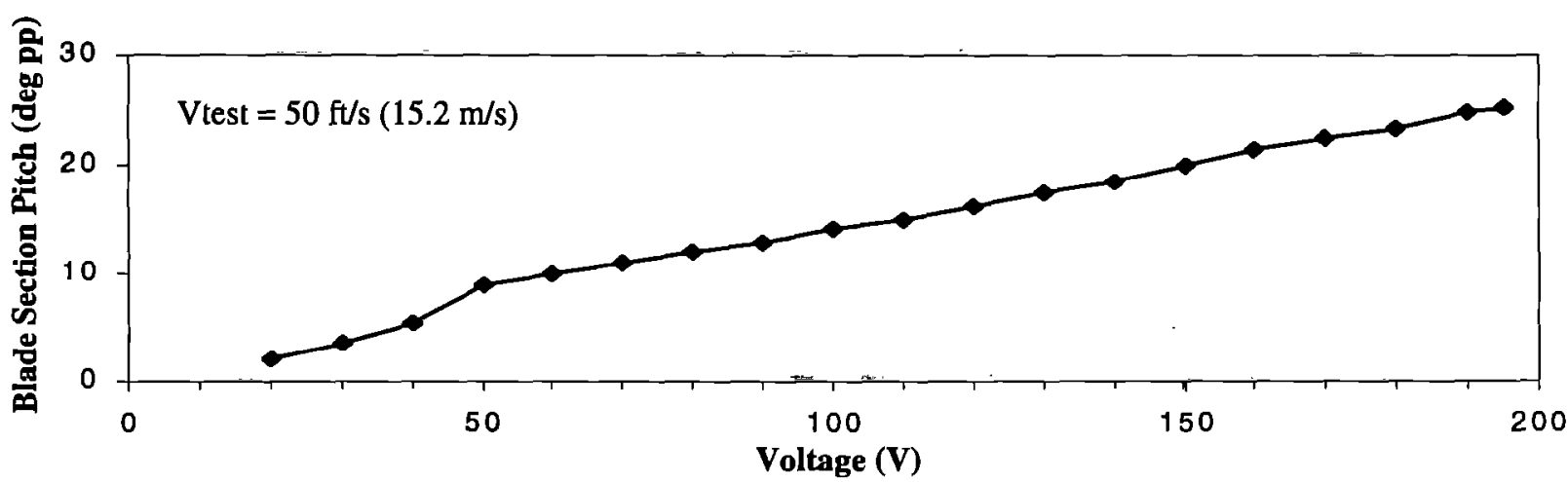

Figure 13: Static Blade Pitch Response The blade section was allowed to pivot around the quarter-chord in response to flap deflections. For applied voltages under $50 \mathrm{~V}$, the flap deflection remains inside the boundary layer causing the nonlinear response. Above $50 \mathrm{~V}$, the blade pitch response becomes linear reaching a maximum deflection of $25^{\circ}$ peak-to-peak at $194 \mathrm{~V}$, $60 \%$ of the rated maximum field. 


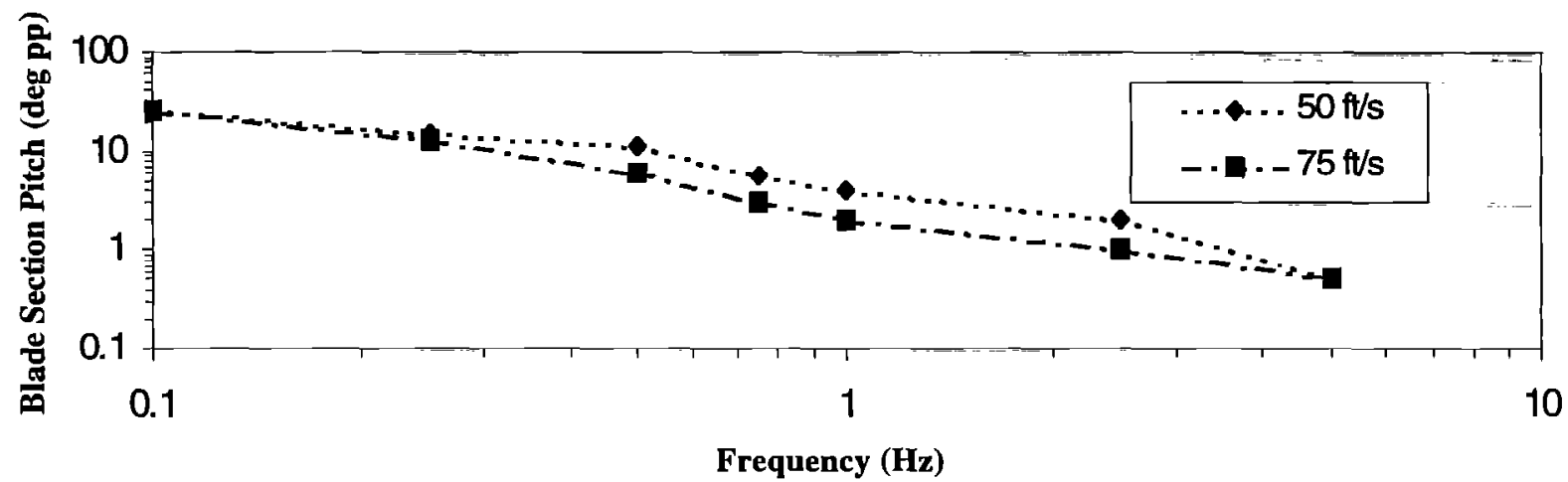

Figure 14: Dynamic Blade Pitch Response The dynamic blade pitch deflection in response to a 0.1 - $5 \mathrm{~Hz}$ flap deflection was examined at tunnel speeds of 50 and $75 \mathrm{ft} / \mathrm{s}$. As frequency was increased to $1 \mathrm{~Hz}$, blade pitch deflection dropped from $25^{\circ}$ peak-to-peak to $4^{\circ}$ peak-to-peak at $50 \mathrm{ft} / \mathrm{s}$, and $2^{\circ}$ peak-to-peak at $75 \mathrm{ft} / \mathrm{s}$.

peak-to-peak at $75 \mathrm{ft} / \mathrm{s}$ were obtained. The loss in deflection with frequency is primarily due to the large inertia of the blade section with respect to the small $10 \%$ chord flap.

Although the free blade dynamic pitch tests were tested at low dynamic pressures and demonstrated a corner frequency of only $0.92 \mathrm{~Hz}$ at $50 \mathrm{ft} / \mathrm{s}$, it is easy to see that wind tunnel testing at speeds of $600 \mathrm{ft} / \mathrm{s}$ would yield a significantly higher system bandwidth. Indeed, at full power and $600 \mathrm{ft} / \mathrm{s}$, the aerodynamic control moments increase to 288 times the level tested, leading to a blade corner frequency of $15.6 \mathrm{~Hz}$. This corresponds to 2.38/rev full blade pitch deflections on a full-scale Bell 206 (which has a 13 in. chord). Given that the C-Block rotor blade section was optimized neither for mass nor inertia minimization, still further improvements to bandwidth levels beyond 3/rev are possible. Accordingly, this system is well suited for control of $\mathrm{HHC}$ and IBC commands as well as flight control from static through $N+1 /$ rev actuation frequencies.

\section{Conclusions}

Any viable active flap system designed to reduce the vibrations present in rotorcraft must be able to generate large flap deflections which are insensitive to airspeed. Without large flap deflections, a significant reduction in vibrations can not be obtained. Also, if the flap deflections are significantly coupled with airspeed, the gusting environment of the helicopter would reduce the effectiveness of the control system and possibly induce control surface lock causing a loss of control.

This paper presents the wind tunnel testing of a new active rotor blade flap system designed to generate large flap deflections independent of airspeed while providing a bandwidth suitable for $\mathrm{HHC}$ and IBC systems. The system utilized high authority C-block actuators coupled to a mass and aerodynamically balanced flap to achieve this goal. The performance of the system was validated in two series of wind tunnel tests: first testing the fixed blade flap deflection, then testing the blade section pitch deflection in response to flap motions. From the wind tunnel testing, the following can be concluded:

- Fixed blade, quasi-static flap deflections in excess of $9^{\circ}$ peak-to-peak were obtained at $60 \%$ of the maximum rated voltage for $\mathrm{PZT}-5 \mathrm{H}$. The deflections were observed to be independent of airspeed from 0 to $100 \mathrm{ft} / \mathrm{s}$. If the voltage is increased to the maximum rated voltage of $340 \mathrm{~V}$ $(10.2 \mathrm{~V} / \mathrm{mil})$ fixed blade flap deflections near $16^{\circ}$ peak-to-peak at $1 \mathrm{~Hz}$ are expected.

- Fixed blade, dynamic flap response testing demonstrated that the first significant resonance frequency occurred near $60 \mathrm{~Hz}$, and the corner frequency exceeded $100 \mathrm{~Hz}$. The bandwidth of 60 $\mathrm{Hz}$ demonstrates potential for control of vibrations occurring at frequencies in excess of $8 /$ rev.

- Testing at $190 \mathrm{~V}$ (60\% of the maximum voltage) produced maximum fixed blade flap deflections of approximately $11.5^{\circ}$ peak-to-peak at $28 \mathrm{~Hz}$ and $17^{\circ}$ peak-to-peak at $45 \mathrm{~Hz}$. Airspeed was observed to only minimally affect flap deflection near resonance due to the increased aerodynamic damping associated with increased airspeeds. The frequency response away from resonance was unaffected by airspeed. If the voltage is increased to the maximum rated voltage of $340 \mathrm{~V}(10.2$ 
$\mathrm{V} / \mathrm{mil}$ ) fixed blade flap deflections near $30^{\circ}$ peakto-peak at $45 \mathrm{~Hz}$ are expected.

- Low frequency blade pitch deflections of $25^{\circ}$ peakto-peak were obtained by driving the active flap at $60 \%$ of the maximum voltage, demonstrating a potential for full rotor control as well as HHC and IBC

- Dynamic blade pitch testing at tunnel speeds of 50 and $75 \mathrm{ft} / \mathrm{s}$ demonstrated a characteristic decay curve and a corner frequency of under $1 \mathrm{~Hz}$. Blade pitch deflections of $4^{\circ}$ peak-to-peak at $50 \mathrm{ft} / \mathrm{s}$, and $2^{\circ}$ peak-to-peak at $75 \mathrm{ft} / \mathrm{s}$ were obtained at $1 \mathrm{~Hz}$.

The results of these wind tunnel tests demonstrated that the C-block actuation system and balanced trailing edge flap are capable of achieving high flap deflections independent of airspeed over a broad frequency range. As a result the active flap system has the potential for use in $\mathrm{HHC}$ and $\mathrm{IBC}$ system to reduce vibration and increase overall rotorcraft performance without the risk of surface lock present in systems which are sensitive to airspeed.

\section{Acknowledgments}

This paper is based upon research supported by the US Army Research Office under grant number DAAH04-96-1-0186.

\section{References}

${ }^{\text {I} E . ~ F . ~ P r e c h t l ~ a n d ~ S . ~ R . ~ H a l l ~ 1997, ~ " D e s i g n ~ o f ~ a ~}$ High Efficiency Discrete Servo-Flap Actuator for Helicopter Rotor Control," in Smart Structures and Materials 1997: Smart Structures and Integrated Systems, M. Regelbrugge, Ed. SPIE Vol. 3041: 158182.

${ }^{2}$ T. Spencer and I. Chopra 1996, "Design and Testing of a Helicopter Trailing Edge Flap with Piezoeletric Stack Actuators," in Smart Structures and Materials 1996: Smart Structures and Integrated Systems, I. Chopra, Ed. SPIE Vol. 2717: 120-131.

${ }^{3}$ M. V. Fulton and R. A. Ormiston 1997, "Hover Testing of a Small-Scale Rotor with On-Blade Elevons," Proc. AHS 53rd Annual Forum, Virginia Beach, Virginia, April 29-May 1.

${ }^{4} \mathrm{O}$. Ben-Zeev and I. Chopra, 1996, "Advances in the development of an intelligent rotor employing smart trailing edge flaps," Smart Materials and Structures, 5: pp. 11-25.

${ }^{5}$ N. A. Koratkar and I. Chopra 1997, "Testing and Validation of a Froude scaled Helicopter Rotor model with Piezo-Bimorph actuated Trailing Edge Flaps," in
Smart Structures and Materials 1997: Smart Structures and Integrated Systems, M. Regelbrugge, Ed. SPIE Vol. 3041: 183-205.

${ }^{6}$ S. R. Hall and E. F. Prechtl 1996, "Development of a piezoelectric servoflap for helicopter rotor control," Smart Materials and Structures, 5:26-34.

${ }^{7}$ F. K. Straub and D. J. Merkley 1997, "Design of a smart material actuator for rotor control," Smart Materials and Structures, 6:26-34.

${ }^{8}$ V. Giurgiutiu, C. A. Rogers, and R. Rusovici 1996, "Solid-State Actuation of Rotor Blade Servo-flap for Active Control," Journal of Intelligent Material Systems and Structures, 7:192-202.

${ }^{9}$ R. Rusovici and H. H. Cudney 1997, "Design and Testing of a Helicopter Trailing Edge Flap with Piezoeletric Stack Actuators," in Smart Structures and Materials 1997: Smart Structures and Integrated Systems, M. Regelbrugge, Ed. SPIE Vol. 3041: 146157.

${ }^{10} \mathrm{R}$. L. Spangler and S. R. Hall, "Piezoelectric Actuators for Helicopter Rotor Control," Paper No. 901076-CP, Proceedings of the $31^{\text {st }}$ Structures, Structural Dynamics and Materials Conference, Long Beach, Califomia, April 2-4, 1990.

${ }^{11}$ Near, C. D., 1996, "Piezoelectric actuator technology," in Smart Structures and Materials 1996: Smart Structures and Integrated Systems, I. Chopra, Ed., Proc. SPIE 2717, pp. 246-258.

${ }^{12}$ J. S. N Paine, and Z. Chaudhry, 1996, "The impact of amplification on efficiency and energy density of induced strain actuators," in Proceedings of the ASME Aerospace Division, AD-Vol. 52, J. C. I. Chang, J. Coulter, D. Brei, D. Martinez, W. Ng, and P. P. Friedman, Eds., ASME, New York: pp. 511-516.

${ }^{13}$ A. J. Moskalik and D. Brei, 1998, "Quasi-Static Behavior of Individual C-Block Piezoelectric Actuators," accepted for publication in the Journal of Intelligent Material Systems and Structures.

${ }^{14}$ D. Brei 1993, "The Development of a Polymeric Piezoelectric Bimorph Microactuator-Based

Macroactuator for an Artificial Hand," PhD Thesis: Arizona State University

${ }^{15} \mathrm{~J}$. W. Clement, D. Brei, and A. J. Moskalik 1998, "Bench-Top Characterization of an Active Rotor Blade Flap System Incorporating C-Block Actuators," in Proceedings of the 39th AIAA/ASME/ASCE/AHS/ ASC Structures, Structural Dynamics, and Materials Conference, Long Beach, CA, Apr. 20-23, 1998. 